\title{
Pancreaticopleural fistula: successful treatment by major-to-minor duodenal papilla rendezvous stenting of the pancreatic duct
}

A 62-year-old man with a history of alcohol abuse was admitted with exertional dyspnea and massive pleural effusion bilaterally. Despite repeated thoracocentesis with placement of a chest tube, the sanguineous pleural effusions remained refractory. Follow-up investigations revealed exudative pleural fluid with a markedly elevated amylase level (34 620 IU/L) and acute pancreatitis with peripancreatic exudation in the transitional area between the head and the body of the pancreas. Endoscopic retrograde cholangiopancreatography showed incomplete pancreas divisum and a short-segment stenosis of the mid pancreatic duct with fistulization into the left pleural cavity ( $\bullet$ Fig. 1 ).

Despite successful intubation of the pancreatic duct via the major duodenal papilla, insertion of a plastic stent was unsuccessful due to extensive kinking of the pancreatic duct in the pancreatic head ( $\bullet$ Fig. 2). However, a Terumo wire was successfully passed through the major papilla and led retrogradely back into the duodenum through the minor papilla ( $\bullet$ Fig. 3). Next, needle-knife papillotomy of the minor papilla was carried out using the Terumo wire as a guide, and a plastic stent $(5 \mathrm{Fr}, 16 \mathrm{~cm})$ was placed in the pancreatic duct, passing the stenotic segment of the duct ( Figs. 3, 4). This successful drainage led to disappearance of the pleural effusions and closure of the pancreaticopleural fistula within days. Follow-up investigation after stent removal showed complete disappearance of the pancreatic duct stenosis and the pancreaticopleural fistula.

Only 37 cases of pancreaticopleural fistula were described in the Western literature from 1990 to 2004 [1]. Endoscopic drainage of the pancreatic duct may lead to successful resolution of such a fistula [2-5]. However, pancreaticopleural fistula in pancreas divisum and its successful treatment using a rendezvous technique between the major and minor duodenal papillae have not been described before.

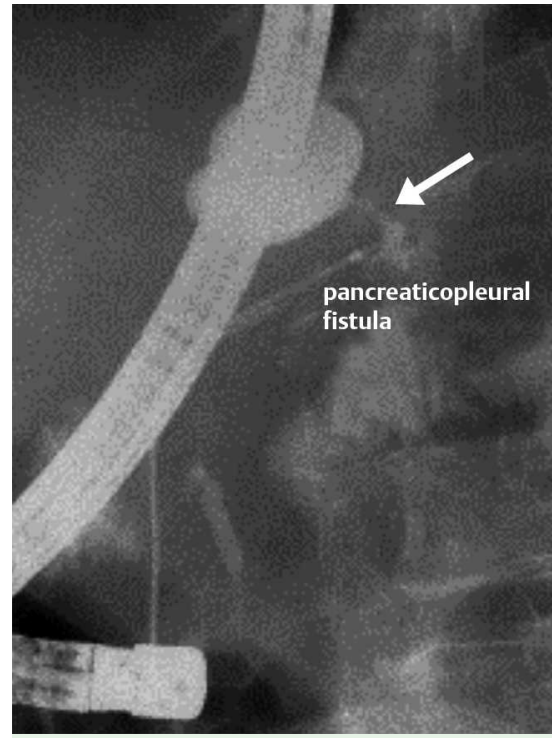

Fig. 1 Endoscopic retrograde cholangiopancreatography (ERCP) via the minor duodenal papilla shows the pancreaticopleural fistula.

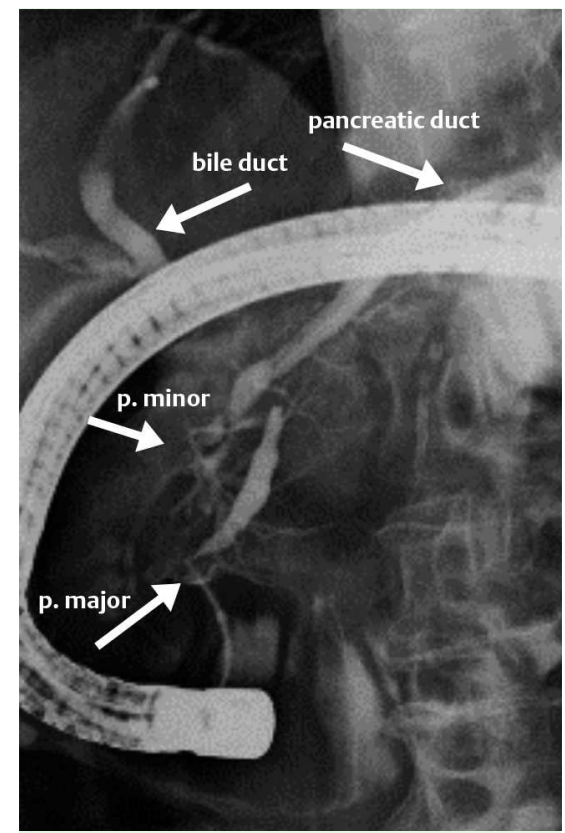

Fig. 2 ERCP shows incomplete pancreas divisum and kinking of the pancreatic duct.

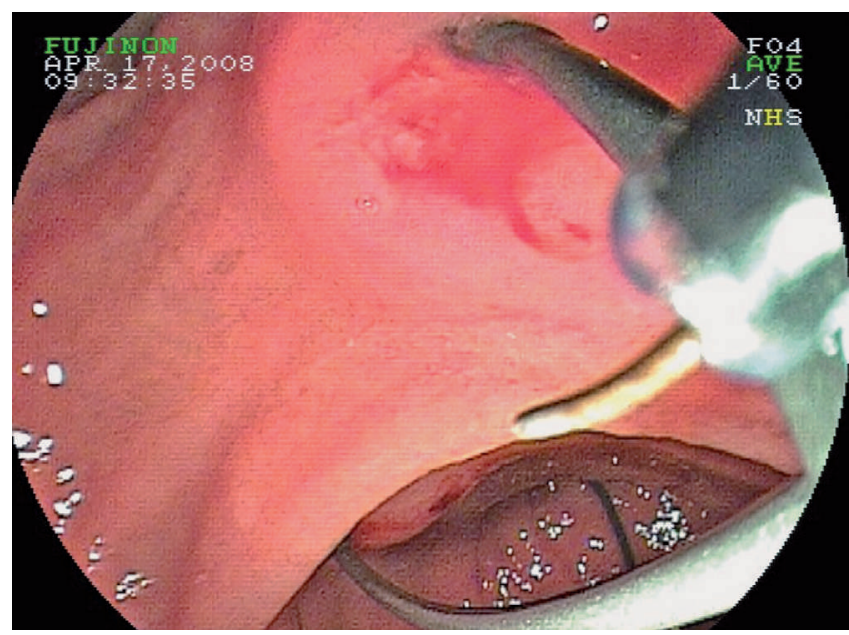

Fig. 3 Position of a Terumo wire, entering the pancreatic duct through the major duodenal papilla and leaving it via the minor papilla into the duodenum. The needle knife is in position preparatory to papillotomy of the minor papilla using the Terumo wire as a guide.

We conclude that endoscopic drainage of the pancreatic duct represents an option for successful treatment of pancreaticopleural fistulas even in anatomically difficult cases.

Endoscopy_UCTN_Code_TTT_1AR_2AC Endoscopy_UCTN_Code_TTT_1AR_2AZ
T. Frieling ${ }^{1}$, M. Bubic ${ }^{1}$, M. Streuter ${ }^{2}$, J. Heise ${ }^{1}$, C. Kreysel ${ }^{1}$

Department of Internal Medicine II, Helios Clinic Krefeld, Krefeld, Germany

2 Department of Pulmology, Helios Clinic Krefeld, Krefeld, Germany 


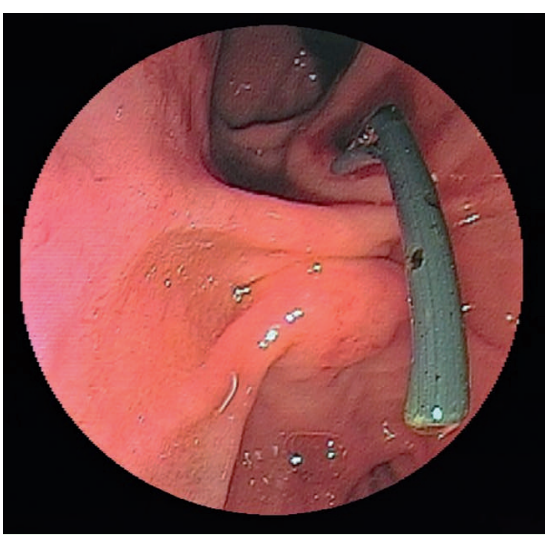

Fig. 4 The plastic tube in place, passing through the minor papilla.

\section{References}

1 Oh YS, Edmundowicz SA, Jonnalagadda SS, Azar RR. Pancreaticopleural fistula: report of two cases and review of the literature. Dig Dis Sci 2006; 51: 1-6

2 Saeed ZA, Ramirez FC, Hepps KS. Endoscopic stent placement for internal and external pancreatic fistulas. Gastroenterology 1993; 105: $1213-1217$

3 Garcia-Ricart F, Croizet O, El Riwini M, Escourrou J. Endoscopic management of a persistent pancreaticopleural fistula. Gastrointest Endosc 1997; 46: 359-361

4 Griesshammer B, Strobel M. Pancreaticopleural fistula treated by transpapillary implantation of a plastic prosthesis. Endoscopy 1998; 30: 741

5 Miyachi A, Kikuyama M, Matsubayashi Y et al. Successful treatment of pancreaticopleural fistula by nasopancreatic drainage and endoscopic removal of pancreatic duct calculi: a case report. Gastrointest Endosc 2004; 59: 454-457
Bibliography

DOI $10.1055 / \mathrm{s}-0029-1214765$

Endoscopy 2009; 41: E179-E180

(c) Georg Thieme Verlag KG Stuttgart · New York . ISSN 0013-726X

Corresponding author

\section{T. Frieling, MD}

Department of Gastroenterology, Hepatology, Infectiology, Neurogastroenterology, Hematology and Oncology

Helios Clinic Krefeld

47805 Krefeld

Lutherplatz 40

Germany

Fax: +49-2151-322078

thomas.frieling@helios-kliniken.de 